Published online: 5 September 2017

(C) The Association of Bone and Joint Surgeons (B) 2017

\title{
Reply to the Letter to the Editor
}

\section{Reply to the Letter to the Editor: False-positive Cultures After Native Knee Aspiration: True or False}

\author{
Jason M. Jennings MD, DPT, Douglas A. Dennis MD, Raymond H. Kim MD, \\ Todd M. Miner MD, Charlie C. Yang MD, David C. McNabb MD
}

To the Editor,

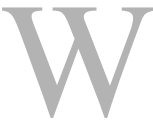
e agree that a culturepositive specimen suggests that bacteria are present, and we agree that the term "false-positive" needs to be revisited. Clinicians cannot cavalierly dismiss any culture result that was properly obtained. This highlights the impor-

(RE: Jennings JM, Dennis DA, Kim RH, Miner TM, Yang CC, McNabb DC. Falsepositive cultures after native knee aspiration: True or false. Clin Orthop Relat Res. 2017;475:1840-1843).

The authors certify that neither they, nor any members of their immediate families, have any commercial associations (such as consultancies, stock ownership, equity interest, patent/licensing arrangements, etc.) that might pose a conflict of interest in connection with the submitted article. All ICMJE Conflict of Interest Forms for authors and Clinical Orthopaedics and Related Research ${ }^{\mathbb{R}}$ editors and board members are on file with the publication and can be viewed on request.

The opinions expressed are those of the writers, and do not reflect the opinion or policy of $C O R R^{\mathbb{R}}$ or The Association of Bone and Joint Surgeons ${ }^{\mathbb{R}}$. tance of meticulous harvesting and laboratory technique when handling specimens.

The anaerobic conditions of an agar with kanamycin and vancomycin may affect the detection of Propionibacterium. Although not included in the manuscript, our laboratory used a blood agar without kanamycin and vancomycin, which would not interfere with the ability of these cultures to detect Propionibacterium.

\section{J. M. Jennings MD, DPT, \\ D. A. Dennis MD $(\varangle)$, R. H. Kim MD, \\ T. M. Miner MD, C. C. Yang MD \\ Colorado Joint Replacement, 2535 S \\ Downing Street, Suite 100, Denver, CO 80210, USA \\ e-mail: roseannjohnson@centura.org}

D. A. Dennis MD, R. H. Kim MD

Department of Biomedical Engineering,

University of Denver, Denver, CO, USA

D. A. Dennis MD

Department of Orthopedics, University of Colorado School of Medicine, Aurora, CO, USA

D. A. Dennis MD

Department of Biomedical Engineering, University of Tennessee, Knoxville, TN, USA

\section{R. H. Kim MD}

Department of Orthopedic Surgery, Marshall University, Huntington, WV, USA

D. C. McNabb MD

Raleigh Orthopedic Clinic, Raleigh, NC, USA 